Check for updates

Cite this: Chem. Commun., 2022, 58,1704

Received 17th November 2021 Accepted 6th January 2022

DOI: $10.1039 / \mathrm{d} 1 \mathrm{cc} 06470 \mathrm{c}$

rsc.li/chemcomm

\section{Rhodium-catalyzed regioselective addition of thioacids to terminal allenes: enantioselective access to branched allylic thioesters $\dagger$}

\author{
A. Ziyaei Halimehjani ${ }^{\mathrm{ab}}$ and B. Breit (D)*b
}

\begin{abstract}
Rhodium-catalyzed regio- and enantioselective hydrothiolation of terminal allenes with thioacids is reported for the atom-economic synthesis of chiral branched allylic thioesters. By using a rhodium(।) catalyst system, diversities of terminal allenes and thioacids afforded the corresponding branched thioesters in excellent regioselectivity, high yield, and good enantioselectivity. This method was also explored for Fmoc-protected aminothioacids for diastereoselective synthesis of the corresponding thioesters.
\end{abstract}

Rhodium-catalyzed regio- and stereoselective coupling of allenes with pronucleophiles is a powerful method for atomeconomic synthesis of branched allylic products. ${ }^{1}$ In this context, recently, we reported an enantioselective synthesis of allylic thioethers and sulfones via intermolecular hydrothiolation reaction of terminal allenes with thiols. ${ }^{2}$ Due to the difficulties associated to the direct synthesis of chiral thiols from simple starting materials and also the cleavage of $\mathrm{C}-\mathrm{S}$ bonds in thioethers to furnish the corresponding thiols, thioesters are introduced as efficient precursors for the synthesis of free thiols. ${ }^{3}$ Chiral thioesters and related thiols are widely present in nature ${ }^{4}$ and biological systems, ${ }^{5}$ and found extensive applications as valuable intermediates in organic synthesis. ${ }^{6}$ The catalytic synthesis of chiral thioesters, thiols and generally the thiolation chemistry has been an active area of research in synthetic organic chemistry and is a challenging task and remains largely unexplored. Although considerable progress in the synthesis of thioesters and thiols via $\mathrm{C}-\mathrm{S}$ bond formation has been made in recent years, ${ }^{7}$ there are limited strategies for the synthesis of allylic thioesters, especially chiral branched allylic thioesters. Sinou et al. reported palladium(0)-catalyzed

${ }^{a}$ Faculty of Chemistry, Kharazmi University, P. O. Box 15719-14911,

49 Mofateh Street, Tehran, Iran. E-mail: ziyaei@khu.ac.ir

${ }^{b}$ Institut für Organische Chemie, Albert-Ludwigs-Universität Freiburg,

Albert Strasse 21, 79104 Freiburg im Breisgau, Germany.

E-mail: bernhard.breit@chemie.uni-freiburg.de

$\dagger$ Electronic supplementary information (ESI) available: Full experimental details, characterization data, and copies of ${ }^{1} \mathrm{H}$ and ${ }^{13} \mathrm{C}$ NMR spectra for all compounds. See DOI: 10.1039/d1cc06470c allylic substitution of various allylic acetates and carbonates with potassium thioacetate to furnish the corresponding linear allylic thioacetates as major product (Scheme 1a). ${ }^{8}$ An asymmetric version of this reaction for symmetrical allylic carbonates was developed by Gais et al. employing the Trost ligand, affording branched allylic esters in good yield and enantioselectivities. ${ }^{9}$ In 2012 , Lee et al. has shown that the addition of thioacids to 3,3-disubstituted cyclopropenes catalyzed by $\mathrm{PPh}_{3} \mathrm{AuNTf}_{2}$ afforded the corresponding linear allylic thioesters as the major regioisomer (Scheme 1b). ${ }^{10}$ According to our knowledge, the only report for the synthesis of chiral branched allylic thioesters has been published by Zhao et al. via a direct iridium-catalyzed asymmetric allylation of KSAc with active allylic carbonates in the presence of KOAc (Scheme 1c). ${ }^{11}$ This method suffers from some drawbacks such as low

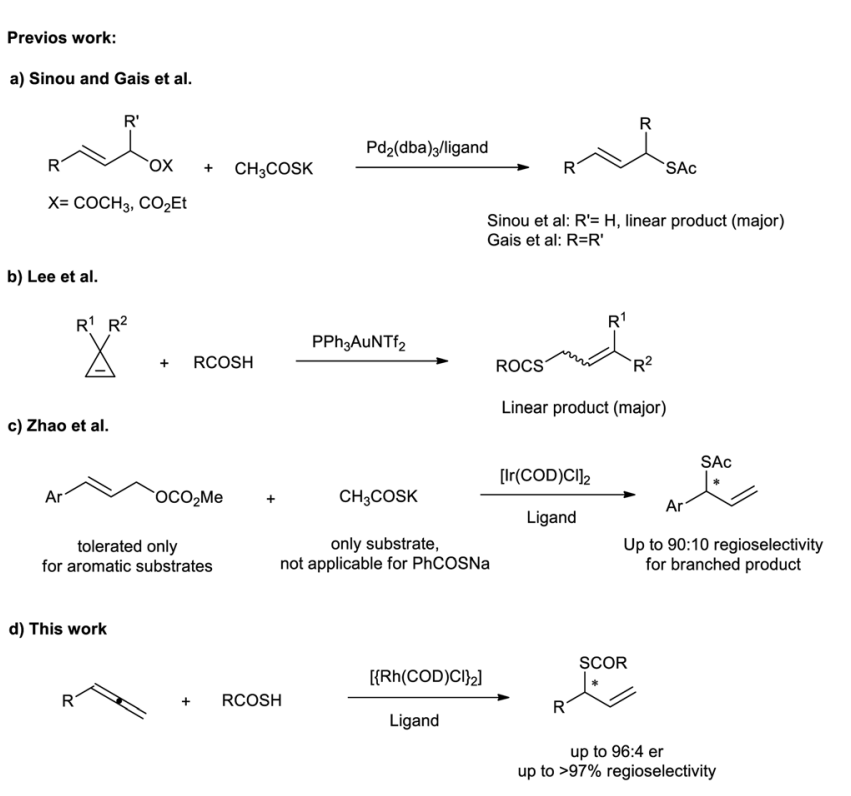

Scheme 1 Published and proposed routes for the synthesis of allylic thioesters. 
regioselectivity and yield for unactivated allylic carbonates and a lack of diversity in thioacid salts. Based on our previous experience on the Rh-catalyzed regioselective and stereoselective allylation reaction using N,O,S,C-nucleophiles/pronucleophiles, ${ }^{12}$ herein, we report the first enantioselective intermolecular hydrothiolation reaction of allenes with thioacids using a rhodium catalyst system to provide chiral branched allylic thioesters (Scheme 1d).

We began by investigating the reaction of hexa-4,5-dien-1ylbenzene (1a) with thiobenzoic acid (2a). No reaction occurred under catalyst-free conditions (Table 1, entry 1). Further experiments were designed to find a suitable ligand for regio- and enantioselective synthesis of branched thioester $\mathbf{3 a}$ using $4 \mathrm{~mol} \%$ of $[\mathrm{Rh}(\mathrm{COD}) \mathrm{Cl}]_{2}, 10 \mathrm{~mol} \%$ of a ligand, and $20 \mathrm{~mol} \%$ of TFA as additive in 1,2-dichloroethane (DCE). After ligand screening, we were delighted to identify that (+)-Binap and $(+)$-DIOP were the most promising ligands, providing $\mathbf{3 a}$ in

Table 1 Optimization of enantioselective hydrothiolation

\begin{tabular}{|c|c|c|c|c|c|c|}
\hline \multicolumn{2}{|c|}{$\begin{array}{l}1 \mathrm{a} \\
\mathrm{R}=\mathrm{PhCH}_{2} \mathrm{CH}_{2} \mathrm{CH}_{2} \\
1 \text { eq }\end{array}$} & \multicolumn{2}{|c|}{$\begin{array}{c}4 \mathrm{~mol} \%\left[\mathrm{rRh}(\mathrm{cod}) \mathrm{Cl} \mathrm{l}_{2]}\right] \\
10 \mathrm{~mol} \% \text { ligand } \\
\text { TFA (20 mol \%) }\end{array}$} & 3a (B) & $3 a(L)$ & $\mathbf{3 a}(\mathrm{M})$ \\
\hline Entry & Ligand & Solvent & $T\left({ }^{\circ} \mathrm{C}\right) / t(\mathrm{~h})$ & Yield $^{a}[\%]$ & 3a $(\mathrm{B}: \mathrm{L}: \mathrm{M})^{b}$ & $\mathrm{ee}^{c}[\%]$ \\
\hline 1 & - & DCE & $\mathrm{rt} / 24$ & Trace & - & - \\
\hline 2 & L1 & DCE & $\mathrm{rt} / 16$ & 20 & $5: 70: 25$ & - \\
\hline 3 & L2 & DCE & $\mathrm{rt} / 16$ & 5 & - & - \\
\hline 4 & L3 & DCE & $\mathrm{rt} / 16$ & 10 & $0: 85: 15$ & - \\
\hline 5 & $\mathrm{~L} 4$ & DCE & $40 / 3$ & 82 & $85: 1: 14$ & 21 \\
\hline 6 & L5 & DCE & $40 / 3$ & 80 & $83: 0: 17$ & -69 \\
\hline 7 & L4 & $\mathrm{CH}_{3} \mathrm{CN}$ & $\mathrm{rt} / 16$ & 80 & $86: 2: 12$ & 10 \\
\hline 8 & L5 & $\mathrm{CH}_{3} \mathrm{CN}$ & $\mathrm{rt} / 16$ & 85 & $97: 1: 2$ & -85 \\
\hline $9^{d}$ & L5 & $\mathrm{CH}_{3} \mathrm{CN}$ & $\mathrm{rt} / 16$ & 85 & $97: 1: 2$ & -87 \\
\hline $10^{d}$ & L6 & $\mathrm{CH}_{3} \mathrm{CN}$ & $\mathrm{rt} / 16$ & 45 & $93: 4: 3$ & 85 \\
\hline $11^{d e}$ & L5 & $\mathrm{CH}_{3} \mathrm{CN}$ & $\mathrm{rt} / 16$ & 63 & $97: 1: 2$ & -83 \\
\hline $12^{d f}$ & L5 & $\mathrm{CH}_{3} \mathrm{CN}$ & $\mathrm{rt} / 16$ & 55 & $95: 2: 3$ & -87 \\
\hline $13^{d g}$ & L5 & $\mathrm{CH}_{3} \mathrm{CN}$ & $\mathrm{rt} / 16$ & 10 & $70: 30: 0$ & - \\
\hline $14^{d h}$ & L5 & $\mathrm{CH}_{3} \mathrm{CN}$ & $\mathrm{rt} / 16$ & 62 & $96: 2: 2$ & -85 \\
\hline $15^{d i}$ & L5 & $\mathrm{CH}_{3} \mathrm{CN}$ & $\mathrm{rt} / 16$ & 70 & $88: 8: 4$ & -85 \\
\hline $16^{d j}$ & L5 & $\mathrm{CH}_{3} \mathrm{CN}$ & $\mathrm{rt} / 16$ & 62 & $80: 20: 0$ & -82 \\
\hline $17^{d k}$ & L5 & $\mathrm{CH}_{3} \mathrm{CN}$ & $\mathrm{rt} / 16$ & 52 & $94: 2: 4$ & -86 \\
\hline
\end{tabular}
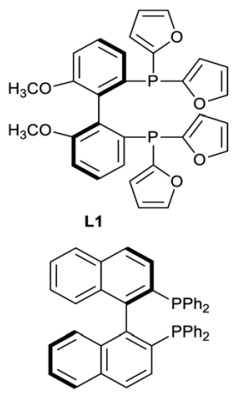

L4

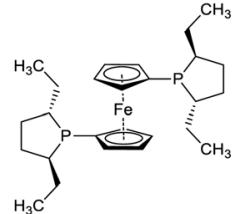

L2

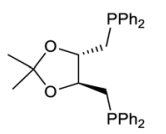

$\mathbf{L 5}$

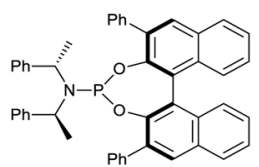

L3

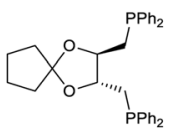

L6
${ }^{a}$ Isolated yield of branched thioester. ${ }^{b}$ Determined by crude NMR. ${ }^{c}$ Determined by HPLC analysis on a chiral stationary phase. ${ }^{d} 8 \mathrm{~mol} \%$ of ligand was used. ${ }^{e} 30 \mathrm{~mol} \%$ of TFA was used. ${ }^{f} 10 \mathrm{~mol} \%$ of TFA was used. ${ }^{g}\left[\left\{\mathrm{Rh}(\operatorname{cod}) \mathrm{OAc}_{2}\right]\right.$ was used as rhodium source. ${ }^{h}$ Solvent $(0.1 \mathrm{M})$ was used. ${ }^{i}$ Solvent $0.2 \mathrm{M}$ was used. ${ }^{j}$ Allene/thioacid ratio was $1: 1.5$. ${ }^{k}$ Starting materials and catalyst were added at the same time. high yield, good regioselectivity and moderate enantioselectivity (Table 1, entries 2-6). Solvent screening at room temperature revealed that $(+)$-DIOP afforded excellent regioselectivity and high ee ( $85 \%$ ) in acetonitrile (Table 1, entry 8 ). By using $8 \mathrm{~mol} \%$ of ligand, the ee was improved to $87 \%$ with similar regioselectivity and yield (Table 1, entry 9). No improvement was observed using other DIOP ligands such as $(R, R)$-DTBM-DIOP (DTBM = (3,5-di-tert-butyl-4-methoxy) and $(R, R)$-Cp-DIOP (Cp = cyclopentyl) (Table 1, entry 10). Varying other parameters in the model reaction such as the amount of TFA, the type of additive, rhodium source, concentration of the reaction, and substrates equivalents didn't improve the reaction significantly (Table 1, entries 11-16). It is notable that premixing of the ligand with $[\mathrm{Rh}(\mathrm{COD}) \mathrm{Cl}]_{2}$ in acetonitrile for 10 minutes is crucial to get the optimal yield and enantioselectivity (Table 1, entry 17).

With the optimized reaction conditions in hand, we investigated the scope of allenes in the regio- and enantioselective synthesis of branched allylic thioesters (Scheme 2). A variety of aliphatic allenes were used successfully in this protocol to give the corresponding thioesters in high yields, excellent regioselectivity $(>96 \%)$ and high ee. Beside simple linear alkylsubstituted allenes (3a-d), allenes with various functional groups such as nitrile (3e), ether (3f), protected alcohols

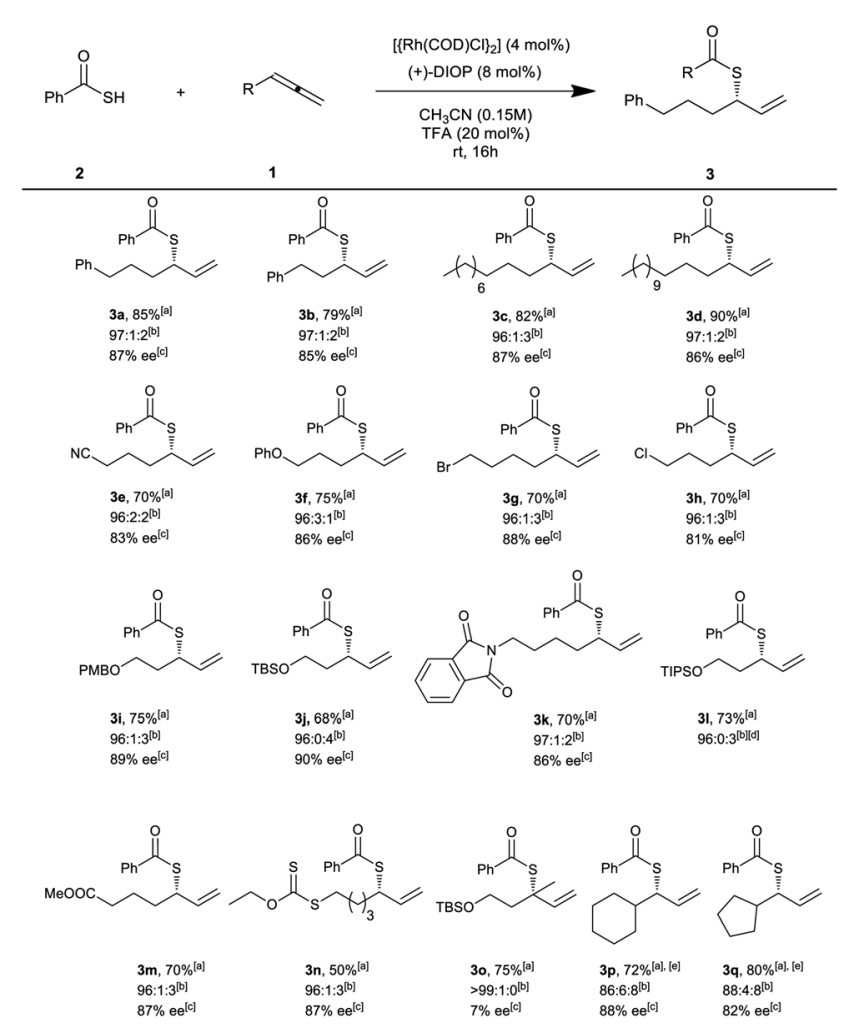

Scheme 2 Scope of allenes with thiobenzoic acid. [a] Isolated yield for branched product. [b] Regioselectivity was determined by ${ }^{1} \mathrm{H}$ NMR analysis of crude reaction mixture. [c] Determined by HPLC analysis on a chiral stationary phase. [d] Attempt to measure the ee of the product was not successful. [e] The reaction was carried out with $(R)$-Xyl-Binap instead of $(+)$-DIOP. PMB $=p$-methoxybenzyl, TBS= tert-butyldimethylsilyl, TIPS = triisopropylsilyl. 
(3j, 31, 3o) (TBS-, TIPS-, and PMB-protected), phthalimide (3k), ester (3m), halide $(\mathbf{3 g}-\mathbf{h})$, and xanthate (3n) were tolerated well in this protocol. For 1,1'-disubstituted allene, the corresponding thioester (3o) was obtained in high yield and excellent regioselectivity, but with poor enantioselectivity. Cyclohexylallene and cyclopentylallene afforded the corresponding thioesters (3p, 3q) in high yield and enantioselectivity, albeit with lower regioselectivity. It is notable that internal allenes are not suitable substrates for this reaction. In addition, unfortunately, aryl-substituted allenes were not compatible in this coupling reaction. The absolute configurations of products were determined as $S$ by chemical correlation with known compounds (see ESI $\dagger$ ).

Next, the generality of this protocol was examined using aliphatic and aromatic thioacids as coupling partner (Scheme 3). Thioacids were prepared in one or two steps from the corresponding carboxylic acid or acyl halides (see ESI $\dagger$ ). ${ }^{13}$ Both aromatic and aliphatic thioacids are suitable substrates for this reaction, affording the corresponding thioesters $\mathbf{4 a - f}$ in high yields, regioselectivity and enantioselectivity. Adamantane-1-carbothioic $S$-acid as a bulky thioacid afforded the corresponding thioester $\mathbf{4 b}$ in $\mathbf{9 2} \%$ ee (Scheme 3 ).

Due to the importance of Fmoc-protected thioester peptide precursors in chemical ligation, ${ }^{14}$ finally, the scope of this reaction was further explored by the use of Fmoc-protectedaminothioacid 5 as coupling partner in the reaction with allene 1a under optimized reaction conditions (Scheme 4). By using L-alanine-based thioacid the corresponding branched thioester 6a was obtained in excellent diastereoselectivity with moderate yield (Scheme 4, path A). It is notable that by using Fmoc-Dalanine thioacid and (-)-DIOP, the opposite enantiomer of $\mathbf{6 a}$ was obtained. It means that the catalyst has complete control on the diastereoselectivity of the reaction. In addition, similar diastereoselectivity was observed using Fmoc-L-alanine thioacid and (-)-DIOP (Scheme 4, path B).

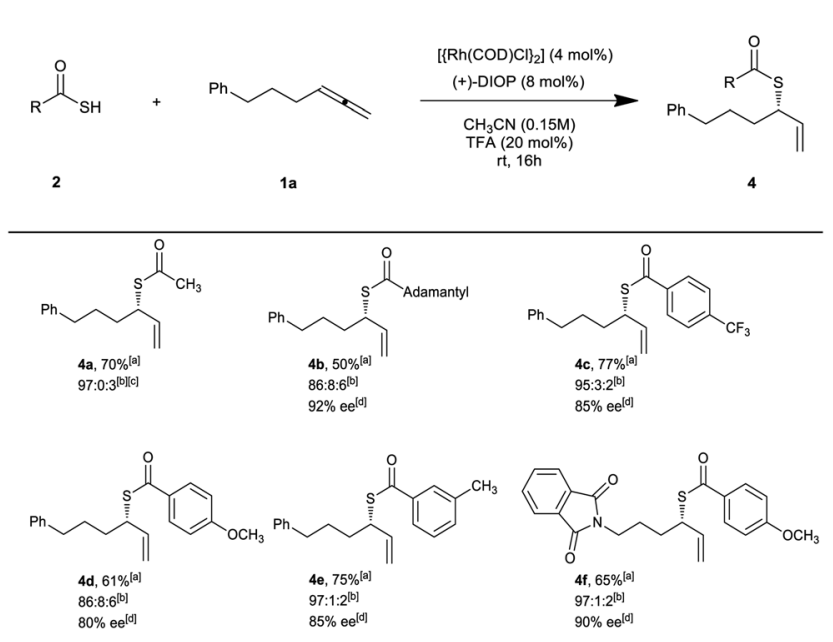

Scheme 3 Scope of thioacids with allene 1a. [a] Isolated yield for Branched product. [b] Regioselectivity was determined by ${ }^{1} \mathrm{H}$ NMR analysis of crude reaction mixture. [c] Attempt to measure the ee of the product was not successful. [d] Determined by HPLC analysis on a chiral stationary phase.

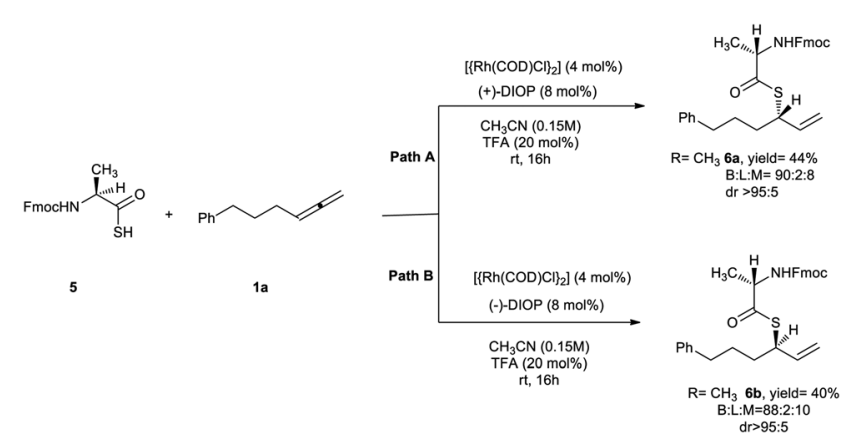

Scheme 4 Aminothioacid in hydrothiolation reaction of terminal allene.

In conclusion, we have developed the first method for the regio- and enantioselective intermolecular hydrothiolation of terminal allenes with thioacids for the preparation of chiral branched thioesters in good to excellent yields. The method is broadly applicable for a wide range of terminal allenes with various functional groups and aromatic and aliphatic thioacids. In addition, this method was explored for Fmoc-protected aminothioacids for diastereoselective synthesis of the corresponding thioesters under complete control of catalyst. This method provides an efficient access to chiral thioesters, which are suitable substrates for the synthesis of chiral thiols after deprotection, and are efficient intermediates in further organic synthesis.

We are grateful to the Alexander von Humboldt foundation for supporting this work. In addition, we are thankful to the research council of Kharazmi University for supporting this work.

\section{Conflicts of interest}

There are no conflicts to declare.

\section{Notes and references}

1 (a) B. Breit, Acc. Chem. Res., 2016, 49, 1524-1536; (b) D. Berthold, A. G. A. Geissler, S. Giofré and B. Breit, Angew. Chem., Int. Ed., 2019, 58, 9994-9997.

2 A. B. Pritzius and B. Breit, Angew. Chem., Int. Ed., 2015, 54, 3121-3125.

3 (a) T. Xu, T. Cao, M. Yang, R. Xu, X. Nie and S. Liao, Org. Lett., 2020, 22, 3692-3696; (b) J. Luo, M. Rauch, L. Avram, Y. Ben-David and D. Milstein, J. Am. Chem. Soc., 2020, 142, 21628-21633; (c) Q. Song, P. Zhang, S. Liang, X. Chen, P. Li and W. Li, Org. Lett., 2020, 22, 7859-7863.

4 (a) K. Chandru, A. Gilbert, C. Butch, M. Aono and H. J. Cleaves, Sci. Rep., 2016, 6, 29883; (b) A. L. Lehninger, D. L. Nelson and M. M. Cox, Principles of Biochemistry, Worth Publishing, New York, 3rd edn, 2000; (c) F. Pietrocola, L. Galluzzi, J. M. Bravo-SanPedro, F. Madeo and G. Kroemer, Cell Metab., 2015, 21, 805-821; (d) Y. E. Du, W. S. Byun, S. B. Lee, S. Hwang, Y. H. Shin, B. Shin, Y. J. Jang, S. Hong, J. Shin, S. K. Lee and D. C. Oh, Org. Lett., 2020, 22, 5337-5341; (e) K. Taori, V. J. Paul and H. Luesch, J. Am. Chem. Soc., 2008, 130, 1806-1807.

5 (a) J. Staunton and K. J. Weissman, Nat. Prod. Rep., 2001, 18, 380-416; (b) K. A. Scott and J. T. Njardarson, Top. Curr. Chem., 2019, 376, 1-34; (c) M. Feng, B. Tang, S. Liang and X. Jiang, Curr. Top. Med. Chem., 2016, 16, 1200-1216.

6 (a) A. P. Pulis, A. Varela, C. Citti, P. Songara, D. Leonori and V. K. Aggarwal, Angew. Chem., Int. Ed., 2017, 56, 10835-10839; 


\section{Communication}

(b) S. Ujiwara and N. Kambe, Top. Curr. Chem., 2012, 251, 87-140; (c) J. M. Villalobos, J. Srogl and L. S. Liebeskind, J. Am. Chem. Soc., 2007, 129, 15734-15735; (d) J. Clayden and P. MacLellan, Beilstein J. Org. Chem., 2011, 7, 582-595; (e) D. Crich and I. Sharma, Angew. Chem., Int. Ed., 2009, 48, 2355-2358; ( $f$ ) D. Crich and K. Sasaki, Org. Lett., 2009, 11, 3514-3517; $(g)$ H. Yang, H. Li, R. Wittenberg, M. Egi, W. Huang and L. S. Liebeskind, J. Am. Chem. Soc., 2007, 129, 1132-1140; (h) D. A. Alonso, S. Kitagaki, N. Utsumi and C. F. Barbas III, Angew. Chem., Int. Ed., 2008, 47, 4588-4591; (i) H. Cao, X. Liu, F. Bie, Y. Shi, Y. Han, P. Yan, M. Szostak and C. Liu, J. Org. Chem., 2021, 86, 10829-10837; $(j)$ H. Ochiai, Y. Uetake, T. Niwa and T. Hosoya, Angew. Chem., Int. Ed., 2017, 56, 2482-2486.

7 (a) J. Luo, M. Rauch, L. Avram, Y. Diskin-Posner, G. Shmul, Y. Ben-David and D. Milstein, Nat. Catal., 2020, 3, 887-892; (b) W. Yu, J. Han, D. Fang, M. Wang and J. Liao, Org. Lett., 2021, 23, 2482-2487; (c) H. J. Ai, F. Zhao, H. Q. Geng and X. F. Wu, ACS Catal., 2021, 11, 3614-3619; (d) X. Qi, Z. P. Bao, X. T. Yao and X. F. Wu, Org. Lett., 2020, 22, 6671-6676; (e) H. J. Ai, W. Lu and X. F. Wu, Angew. Chem., Int. Ed., 2021, 60, 17178-17184; $(f)$ M. Roggen and E. M. Carreira, Angew. Chem., Int. Ed., 2012, 51, 8652-8655; $(g)$ S. Zheng, N. Gao, W. Liu, D. Liu, X. Zhao and T. Cohen, Org. Lett., 2010, 12, 4454-4457; (h) S. Zheng, W. Huang, N. Gao, R. Cui, M. Zhang and X. Zhao, Chem. Commun., 2011, 47, 6969-6971; (i) W. Huang, S. Zheng, J. Tang and X. Zhao, Org. Biomol. Chem., 2011, 9, 7897-7903; (j) M. R. Monaco, S. Prevost and B. List, J. Am. Chem. Soc.,
2014, 136, 16982-16985; (k) V. Hirschbeck, P. H. Gehrtz and I. Fleischer, Chem. - Eur. J., 2018, 24, 7092-7107.

8 S. Divekar, M. Safi, M. Soufiaoui and D. Sinou, Tetrahedron, 1999, 55, 4369-4376.

9 B. J. Lussem and H. J. Gais, J. Org. Chem., 2004, 69, 4041-4052.

10 R. J. Mudd, P. C. Young, J. A. Jordan-Hore, G. M. Rosair and A. L. Lee, J. Org. Chem., 2012, 77, 7633-7639.

11 N. Gao and X. Zhao, Eur. J. Org. Chem., 2013, 2708-2714.

12 (a) J. P. Schmidt and B. Breit, Angew. Chem., Int. Ed., 2020, 59, 23485-23490; (b) A. M. Haydl, K. Xu and B. Breit, Angew. Chem., Int. Ed., 2015, 54, 7149-7153; (c) T. M. Beck and B. Breit, Angew. Chem., Int. Ed., 2017, 56, 1903-1907; (d) V. Khakyzadeh, Y. H. Wang and B. Breit, Chem. Commun., 2017, 53, 4966-4968; (e) Y. H. Wang and B. Breit, Chem. Commun., 2019, 55, 7619-7622.

13 M. Toriyama, H. Kamijo, S. Motohashi, T. Takido and K. Itabashi, Phospho. Sulf. Silic., 2003, 178, 1661-1665.

14 (a) V. P. Terrier, H. Adihou, M. Arnould, A. F. Delmas and V. Aucagne, Chem. Sci., 2016, 7, 339-345; (b) N. Naruse, K. Ohkawachi, T. Inokuma, A. Shigenaga and A. Otaka, Org. Lett., 2018, 20, 2449-2453; (c) J. B. BlancoCanosa and P. E. Dawson, Angew. Chem., Int. Ed., 2008, 47, 6851-6855; (d) A. Kar, J. Mannuthodikayil, S. Singh, A. Biswas, P. Dubey, A. Das and K. Mandal, Angew. Chem., Int. Ed., 2020, 59, 14796-14801; (e) R. Okamoto, K. Morooka and Y. Kajihara, Angew. Chem., Int. Ed., 2012, 51, 191-196. 